\title{
Tympanomeatal Degloving Technique Versus Ring Graft Underlay Technique in Tympanoplasty Type I for Subtotal Perforations
}

\author{
AHMED M.M. HESHMAT, M.S.c.; MAHMOUD A.E. HAGRASS, M.D.; \\ MOHAMED N.A. EL-SHEIKH, M.D. and HASSAN M. HEGAZI, M.D. \\ The Department of Otorhinolaryngology, Faculty of Medicine, Tanta University, Tanta, Egypt
}

\begin{abstract}
Background: Tympanoplasty is an operative procedure used in the reconstruction of a perforation of the tympanic membrane (TM). Two classic methods for reconstruction of a TM perforation have been used: The underlay or overlay graft techniques. Each of these approaches and techniques has its advantages and disadvantages $[\mathbf{1 , 2 , 3}]$
\end{abstract}

Objectives: The aim of this study was to evaluate the outcomes of tympanoplasty type I performed with overlay temporalis fascia using tympanomeatal degloving technique and to compare them with results of tympanoplasty type I performed with underlay ring graft [modified cartilage perichondrium composite graft, CPCG].

Patients and Methods: This study is a comperative prospective study carried out in ORL-HNS Department in Tanta University Hospital, operative procedures was done in the period from October 2015 to February 2016 Study followed by 3 month follow-up for each case, population was fortyeight consecutive cases of subtotal TM perforation undergoing type one tympanoplasty.

The patients were divided into 2 surgical groups [I\&II], 24 ears each. Group (I) is treated by using tympanomeatal degloving technique \& overlay temporalis fascia. While Group (II) is treated by using ring graft underlay technique.

Results: Fascia group showed better hearing results [the change in ABG was (mean: 12.6 \pm 5.2$) \mathrm{dB}$ ] than the Ring group [the change of $\mathrm{ABG}$ was (mean: $11.6 \pm 3.9) \mathrm{dB}$ ] but the difference between both groups is statistically insignificant.

The graft success rate in (group 1 ) was $83.3 \%$. Only 4 cases $(16.7 \%)$ developed post operative perforations. In (group II) the success rate was $95.8 \%$. Only one case $(4.2 \%)$ developed post operative perforation. The difference in the graft success rates between the 2 groups is statistically insignificant $(p>0.05)$

Conclusion: Both techniques we used in this study were very effective in closing subtotal large perforations of TM. Ring group showed better healing results but the difference between both groups is statistically insignificant $(p>0.05)$.

Correspondence to: Dr. Ahmed M.M. Heshmat, E-mail: narutobleachclaymore@hotmail.com
Fascia group showed better hearing results but the difference between both groups is statistically insignificant.

Key Words: Tympanoplasty - Overlay graft - Temporalis fascia graft-Cartilage perichondrium and ring graft.

\section{Introduction}

TYMPANOPLASTY is an operative procedure used in the reconstruction of a perforation of the tympanic membrane (TM). Three main approaches are used in tympanoplasty: Transcanal, endaural, and postauricular, and two classic methods for reconstruction of a TM perforation have been used: the underlay or overlay graft techniques (These terms refer to the position of the graft in relation to the fibrous annulus, not to the malleus or tympanic remnant). Each of these approaches and techniques has its advantages and disadvantages $[1,2,3]$.

The biggest disadvantage of medial graft is its limited exposure and poor utility for larger perforations and its difficulty with repair of near-total perforations. Advantages of the lateral graft technique include wide exposure and versatility for larger perforations and for any needed ossicular reconstruction. Disadvantages include the requirement of a higher technical skill level, a longer operative time, slower healing rate, and the risk of blunting and lateralization of the graft. Marginal, subtotal, or total perforations, known to have a worse outcome whilst utilizing the standard postauricular tympanoplasty technique $[\mathbf{1 , 2}]$.

Tympanomeataldegloving technique used with overlay grafting. In which the skin of the deep external auditory canal is elevated in continuity with the outer epithelial layer of the tympanic membrane and kept attached laterally and anteriorly as a flap. This expose the whole tympanic mem- 
brane remnants for proper application of the overlay graft.

Various materials exist for use for tympanic membrane grafting. True temporalis fascia is the most common graft because of its ease of harvest and its abundant availability, even in revision cases. Some surgeons prefers loose areolar fascia (also known as "fool's fascia") and prefer to save the true fascia for revision cases. Also, the "fool's fascia" is considered by some to be more pliable, have less donor site morbidity, and to be more transparent after healing. It is available via the same postauricular incision that can be used for tympanoplasty, or a separate incision can be made in or beyond the postauricular hairline if a transcanal or endaural technique is used. A mild amount of donor site morbidity occurs, with postoperative pain over the temporalis muscle being the most common symptom. Cartilage is available to be harvested easily from either the tragus or the conchal bowl, if a post-auricular approach is being used. Tragal cartilage is harvested with perichondrium attached via a small incision on the internal surface of the tragus [4]. This graft is an appropriate size and carries very little donor site morbidity. In addition, the perichondrium can be reflected to stabilize the graft. Conchal cartilage also carries no additional significant morbidity. Other grafting materials include lobular fat, periosteum, perichondrium, vein, and Allo Derm [4]. Ring graft is a modified cartilage perichondrium composite graft [CPCG] [5.6]

\section{Patients and Methods:}

This prospective study was carried out in ORLHNS Department in Tanta University Hospital in the period from October 2015 to February 2016. Study population was forty-eight consecutive casesof subtotal TM perforation undergoing type one tympanoplasty.

Patients were divided into 2 surgical groups [I\&II], 24 ears each. Group (I) is treated by using tympanomeatal degloving technique \& overlay temporalis fascia. While Group (II) is treated by using ring graft underlay technique.

All patients approved to participate in the study by signing an informed consent.

\section{Inclusion criteria:}

- Dry subtotal tympanic membrane perforation Fig.

(1).

- Dry for atleast 3 month.

- Adult.

- Moderate conductive hearing loss.
Exclusion criteria:

- Cholesteatoma cases.

- Cases that need ossiculoplasty, any contraindications for general anaethesia.

- Revision tympanoplasty cases.

- Patients below age of 18 years.

- Active ear discharge.

These patients were subjected to:

- Detailed history taking.

- Complete general examination.

- Complete ENT examination.

- Otoscopic and microscopic examination of ears.

- Audiological evaluation.

- Pure tone audiometry.

- Routine investigations for anesthesia.

Follow-up: Routine follow-up for at least 3 months consists of otomicroscopic examination and audiometric evaluation. A successful outcome was considered to comprise complete healing ofthe graft without perforation, retraction, lateralization or blunting, for atleast 3 months post-operatively. Patient's post operative pure tone average air-bone gap compared with pre-operative levels.

\section{Surgical technique:}

All patients were operated upon under general anesthesia. The post-auricular approach was used in all cases. in both groups refreshing the edge of the TM perforation was done (Fig. 2).

In group I, temporalis fascia graft were used. Tympanomeatal degloving technique (Fig. 3) used with overlay grafting.

In which the skin of the deep external auditory canal is elevated in continuity with the outer epithelial layer of the tympanic membrane and kept attached laterallyandanteriorly at 11 to 1 o'clock as a flap (Figs. 4,5).

This will expose the bony canal walls and the whole tympanic membrane remnants for proper application of the overlay graft (Figs. 6,7).

The graft should pass under the handle of the malleus to prevent lateralization. Drilling any overhanging canal wall for proper visualization as well as the anterior tympanomeatal angle to minimize or to prevent blunting.

In group II, the tragal cartilage is taken. The perichondrium was left attached to the concave anterior side (lateral) of the cartilage, leaving the posterior perichondrium and the free edge of the 
tragal cartilage intact, to avoid tragal deformity. The graft was approximately $12-15 \mathrm{~mm}$ in diameter. A circular piece of cartilage was cut from the centre of the graft using a number 15 scalpel blade or the sharp edge of an ear speculum. The cut, circular piece of cartilage was removed with gentle dissection. Care was taken to avoid laceration of the attached perichondrial sheet. In this way, it was possible to obtain a perichondrial sheet with attached cartilage ring frame. The cartilage ring was trimmed according to the periphery needed, taking care to preserve a good rim of firm, elastic, intact cartilage $(2-3 \mathrm{~mm})$, so that the size of the graft would be a little larger than the size of the membrane tensa Figs. $(10,11,12)$.

After preparation of the middle ear and tympanic membrane, the graft was used as an underlay with its cartilage facing medially and its perichondrium facing laterally. We put the graft medial to the handle of malleus. The graft is covered by the tympanic membrane remnant and the posterior tympano-meatal flap repositioned back. Care was taken to place the graft well under the annulus. In both groups, Gelfoam was used to pack the external ear canal lateral to the reconstructed tympanic membrane without putting Gelfoam in the middle ear in both groups.

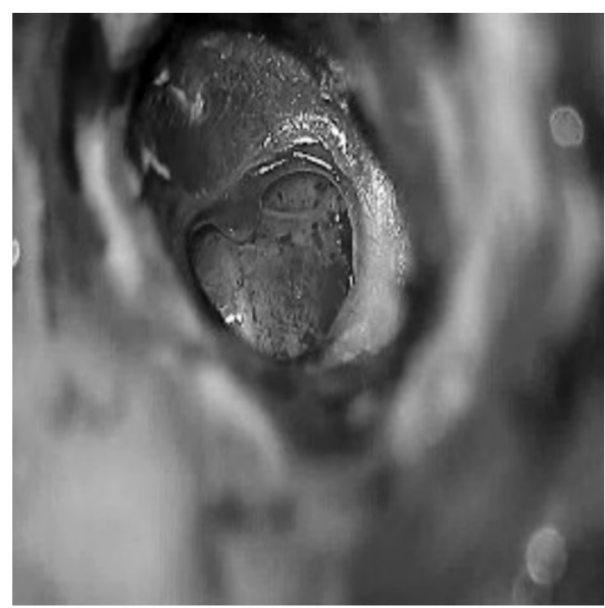

Fig. (1): Microscopic view of subtotal DCP (RT. ear).

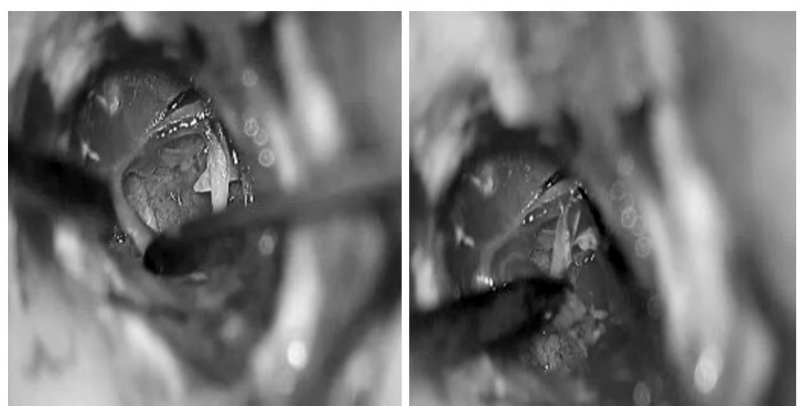

Fig. (2): Refreshing the edge of the DCP (RT. ear).
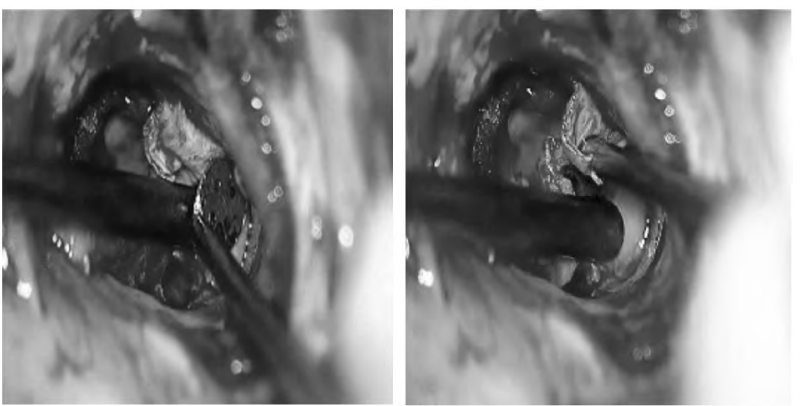

Fig. (3): Degloving and elevation of the skin of EAC as tympanomeatal flap (RT. ear).
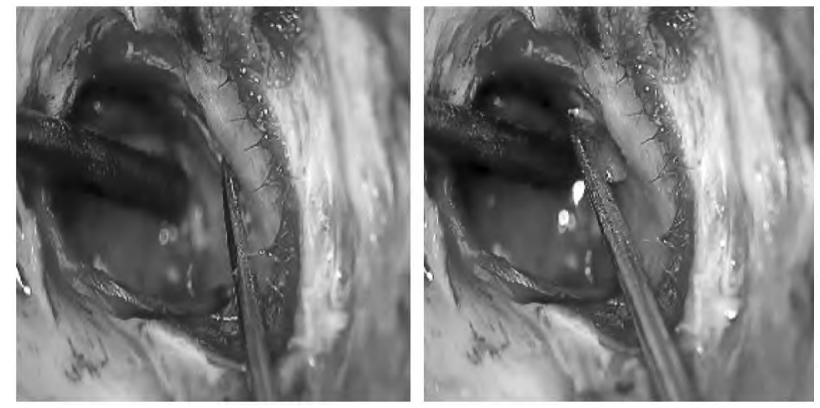

Fig. (4): Horizontal incisions of EAC skin: Anterior to 1 o'clock (RT. ear).

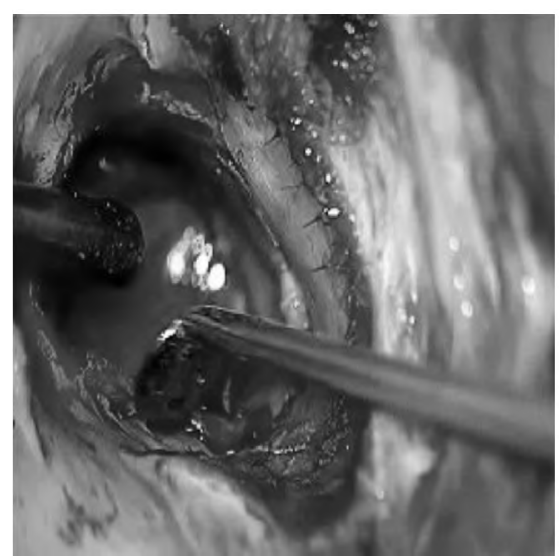

Fig. (5): Horizontal incisions of EAC skin: Posterior to to 11 o'clock (RT. ear).

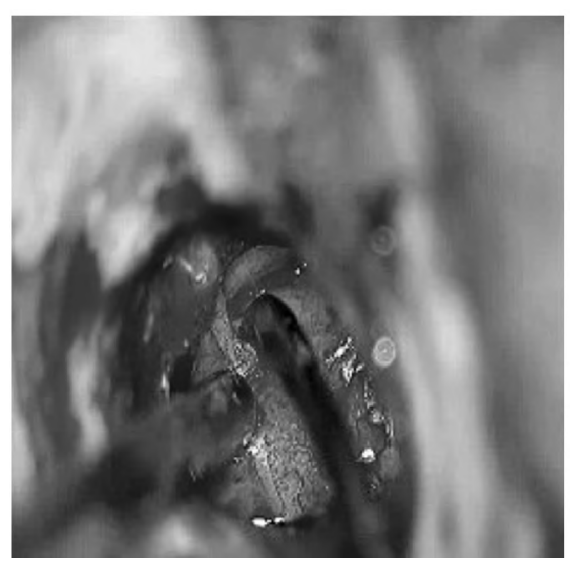

Fig. (6): Cleaning the handle of malleus from any attached epithelium (RT. ear). 


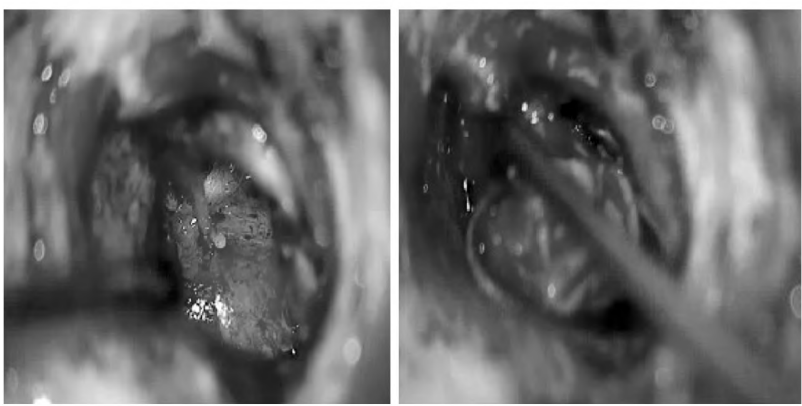

Fig. (7): Exposing TM remnants (RT. ear).
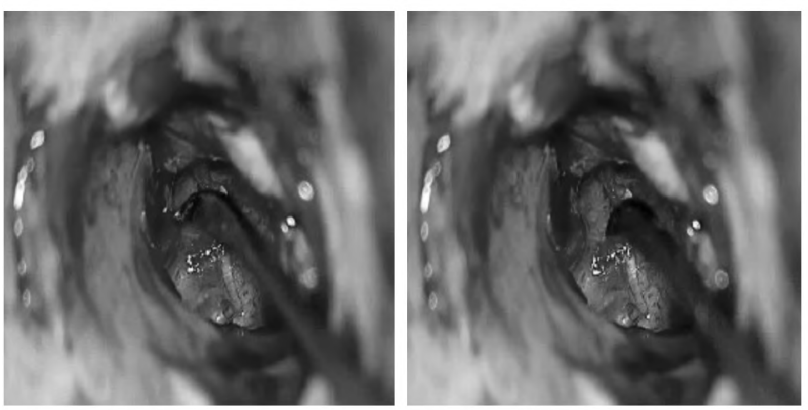

Fig. (8): Testing ossicles mobility (RT. ear).
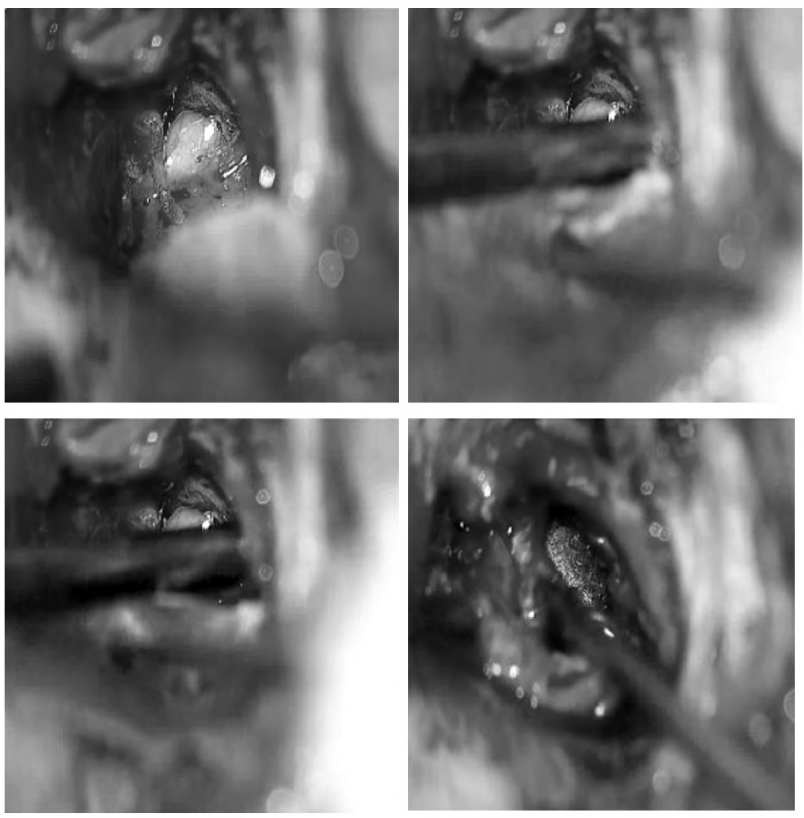

Fig. (9): Placement of TF graft in place (RT. ear).

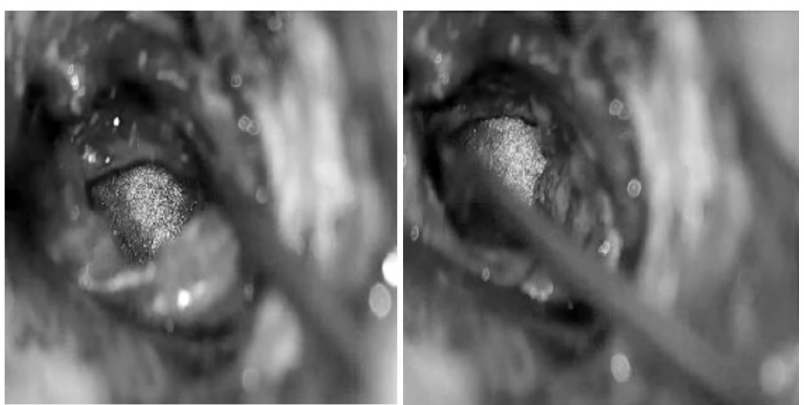

Fig. (10): TF graft in place on lay and replacement of tympanomeatal flap (RT. ear).
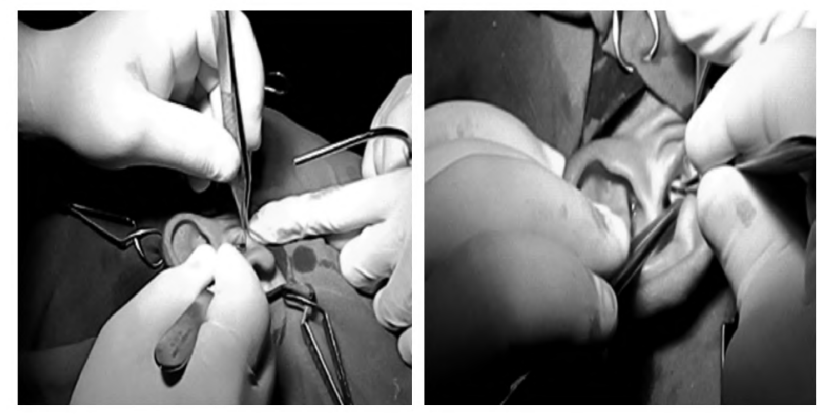

Fig. (10A,B): Harvesting tragal cartilage perichondrium graft.

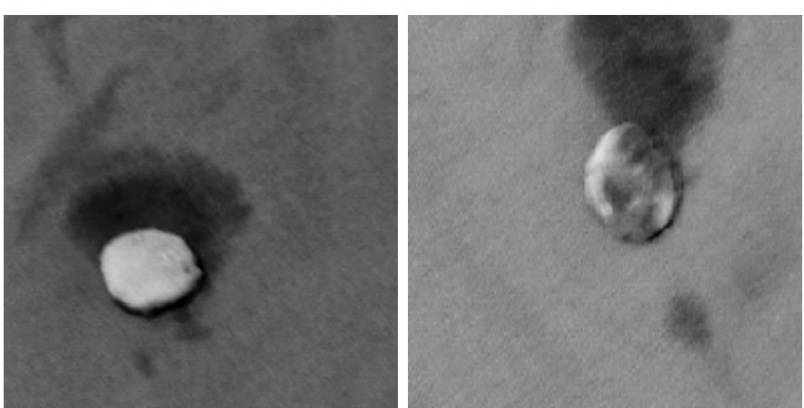

Fig. (11A,B): Cartilage graft with perichondrium on one side.
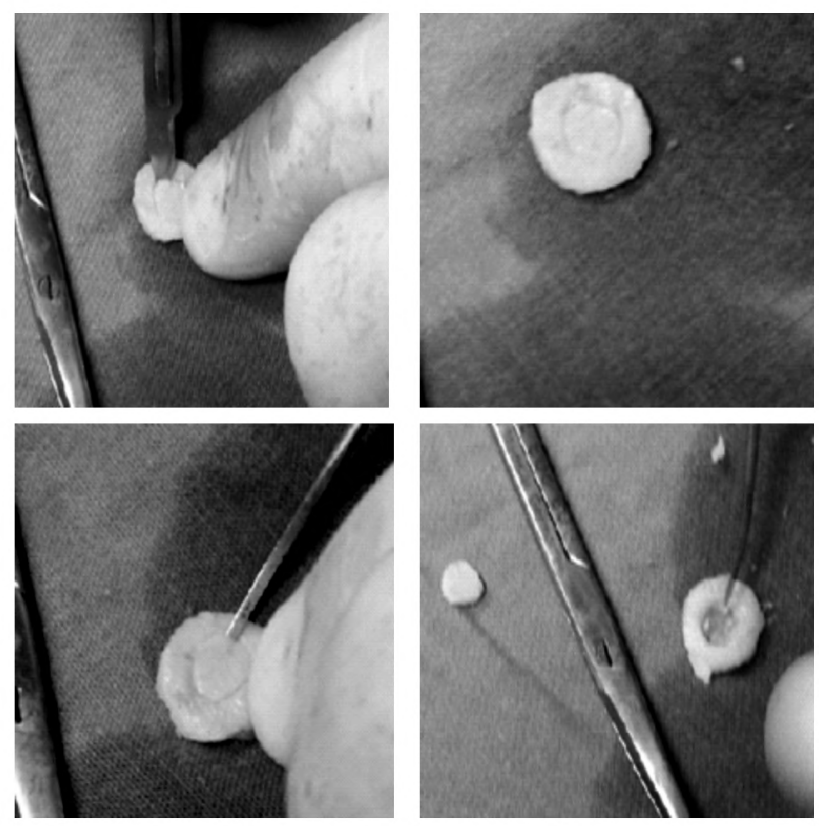

Fig. (12 A,B,C,D): Preparation of the ring graft.

\section{Results}

In this study the total number of patients was 48. The study composed of two groups. Group I (tympanomeateal degloving technique using temporalis fascia) comprised of 24 patients and group II (the ring graft) comprised of 24 patients.

In (group I) the age ranged from 20 years to 45 years with a mean age of $29.3 \pm 7.8$ years. In (group II) the age ranged from 20 years to 47 years with mean age of $29.5 \pm 8.7$ years, (Table 1 and Fig. 13). 
In (group I) there were 16 males $(66.7 \%)$ and 8 females (33.3\%), In (group II), there were 14 males $(58.3 \%)$ and 10 females $(41.7 \%)$, (Table 2 and Fig. 14).

Table (1): Sociodemographic characteristics of all study patients.

\begin{tabular}{cl}
\hline Characteristics & $(\mathrm{n}=100) \mathrm{n} .(\%)$ \\
\hline Age (in years): & \\
Mean \pm S.D & $29.4 \pm 8.2$ \\
Range & $20-47$ \\
Gender: & \\
Male & $30(62.5 \%)$ \\
Female & $18(37.5 \%)$ \\
\hline
\end{tabular}

Table (2): Socio-demographic characteristics of the studied patient groups.

\begin{tabular}{cllll}
\hline Characteristics & \multicolumn{1}{c}{$\begin{array}{c}\text { Group I } \\
(\mathrm{n}=24)\end{array}$} & $\begin{array}{c}\text { Group II } \\
(\mathrm{n}=24)\end{array}$ & $\begin{array}{l}\text { Sig. } \\
\text { test }\end{array}$ & $p$ \\
\hline Age (in years): & & & & \\
Mean \pm S.D & $29.3 \pm 7.8$ & $29.5 \pm 8.7$ & $t$ & \\
Range & $20-45$ & $20-47$ & 0.122 & 0.903 \\
Gender: & & & & \\
Male & $16(66.7 \%)$ & $14(58.3 \%)$ & $\chi^{2}$ & \\
Female & $8(33.3 \%)$ & $10(41.7 \%)$ & 0.356 & 0.551 \\
\hline$t:$ Independent sample $t$-test. & $\chi^{2}:$ Chi square test.
\end{tabular}

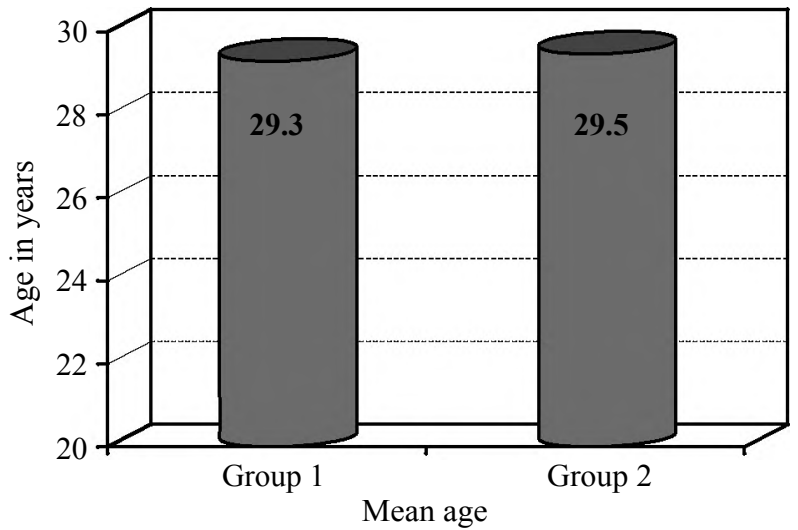

Fig. (13): Mean age of both groups.

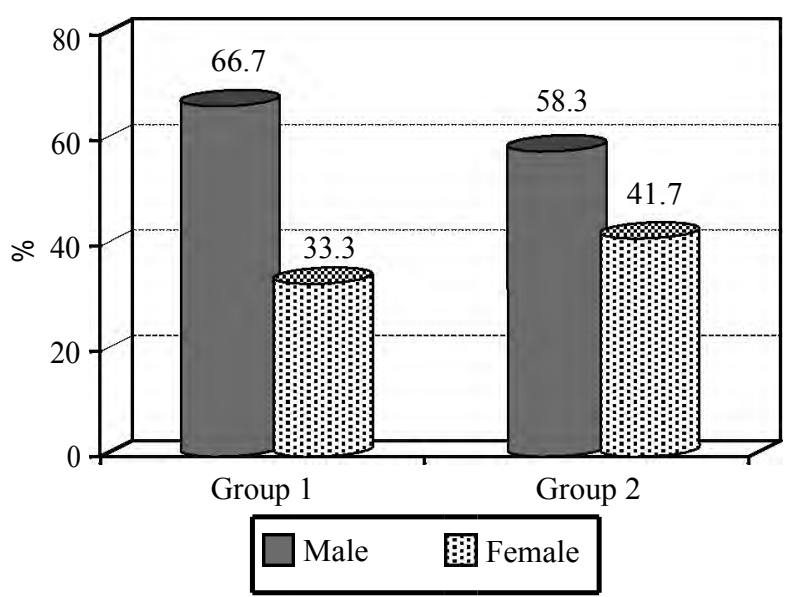

Fig. (14): Gender distribution of both groups.
All patients of both study groups had a subtotal perforation.

Change in ABG (group I) is (mean: 12.6 \pm 5.2 ) $\mathrm{dB}$. This difference is statistically significant $(p<0.001)$, (Table 3 and Fig. 15).

Table (3): Air Bone Gap preoperative and post-operative in Group I.

\begin{tabular}{llll}
\hline $\begin{array}{l}\text { Air Bone Gap } \\
\text { (in dB) }\end{array}$ & Mean \pm S.D & $t$ & $p$ \\
\hline Pre-operative & $\begin{array}{l}22.0 \pm 7.7 \\
9.8 \pm 4.5\end{array}$ & 10.180 & $0.001 *$ \\
Post-operative & \multicolumn{2}{c}{$t$} & \\
\hline$t$ : One sample $t$-test. & *: Statistically significant difference.
\end{tabular}

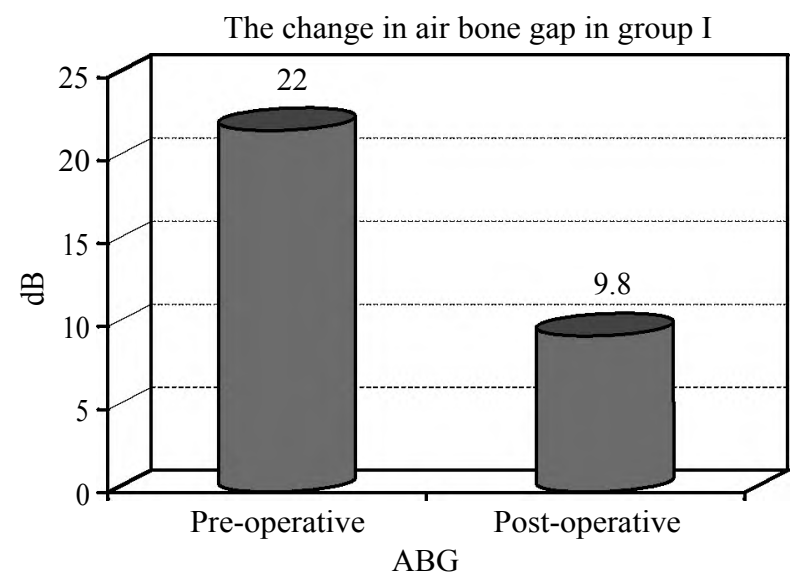

Fig. (15): Change in Air bone Gap in group I.

Change of ABG (group II) is (mean:11.6 \pm 3.9 ) $\mathrm{dB}$, This difference is statistically significant $(p<0.001)$, (Table 4 and Fig. 16).

Table (4): Air Bone Gap preoperative and post-operative in Group II.

\begin{tabular}{llll}
\hline $\begin{array}{l}\text { Air Bone Gap } \\
\text { (in dB) }\end{array}$ & Mean \pm S.D & $t$ & $p$ \\
\hline Pre-operative & $\begin{array}{l}21.0 \pm 7.6 \\
10.5 \pm 5.5\end{array}$ & 10.317 & $0.001 *$ \\
Post-operative & *: Statistically significant difference.
\end{tabular}

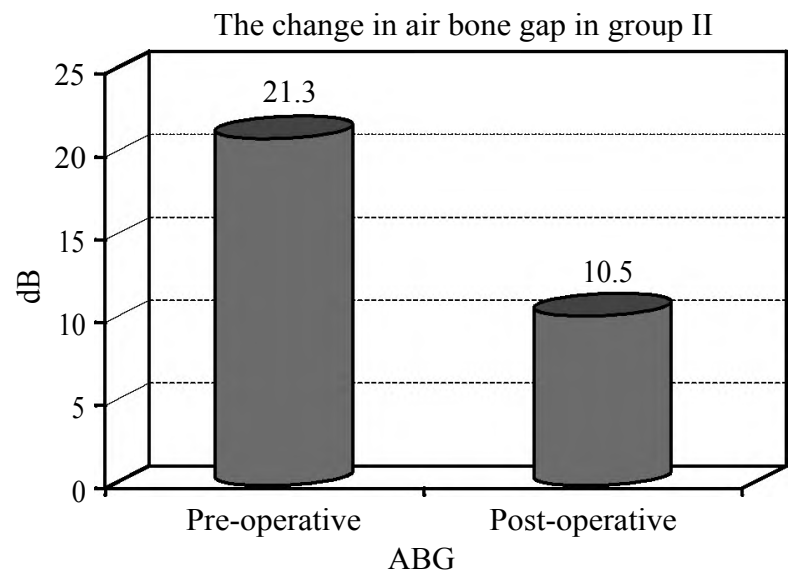

Fig. (16): Change in Air bone Gap in group II. 
The difference in ABG change in both groups is statistically insignificant, $(p>0.05)$, (Table 5 and Figs. 17,18,19).

Table (5): Air Bone Gap preoperative and post-operative among both study groups.

\begin{tabular}{llcc}
\hline $\begin{array}{l}\text { Air Bone Gap } \\
\text { (in dB) }\end{array}$ & Mean \pm S.D & $t$ & $p$ \\
\hline $\begin{array}{l}\text { Pre-operative: } \\
\quad \text { Group I }\end{array}$ & $22.0 \pm 7.7$ & 0.340 & 0.736 \\
$\quad$ Group II & $21.3 \pm 7.6$ & & \\
Post-operative: & & & \\
$\quad$ Group I & $9.8 \pm 4.5$ & $0.465-$ & 0.644 \\
$\quad$ Group II & $10.5 \pm 5.3$ & & \\
The change in $A B G:$ & & & \\
$\quad$ Group I & $12.6 \pm 5.2$ & 0.750 & 0.457 \\
$\quad$ Group II & $11.6 \pm 3.9$ & & \\
\hline
\end{tabular}

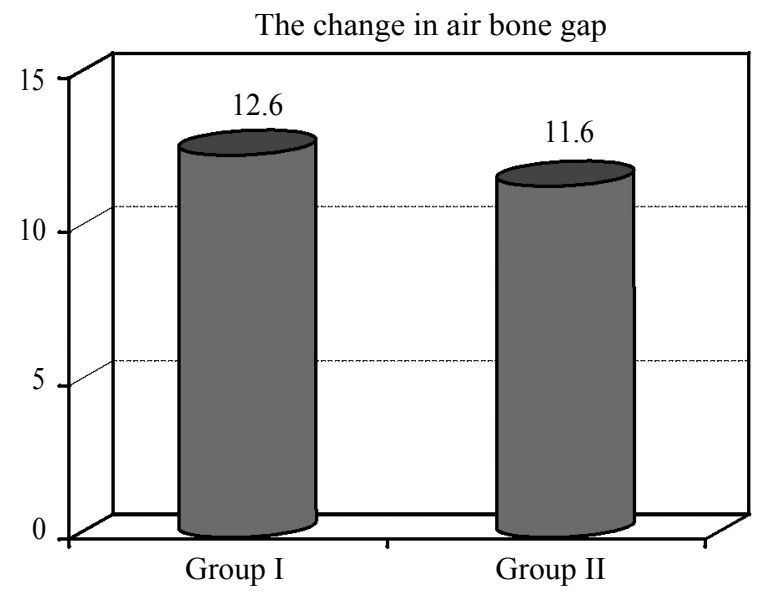

Fig. (17): Change in Air Bone Gap in both study groups.

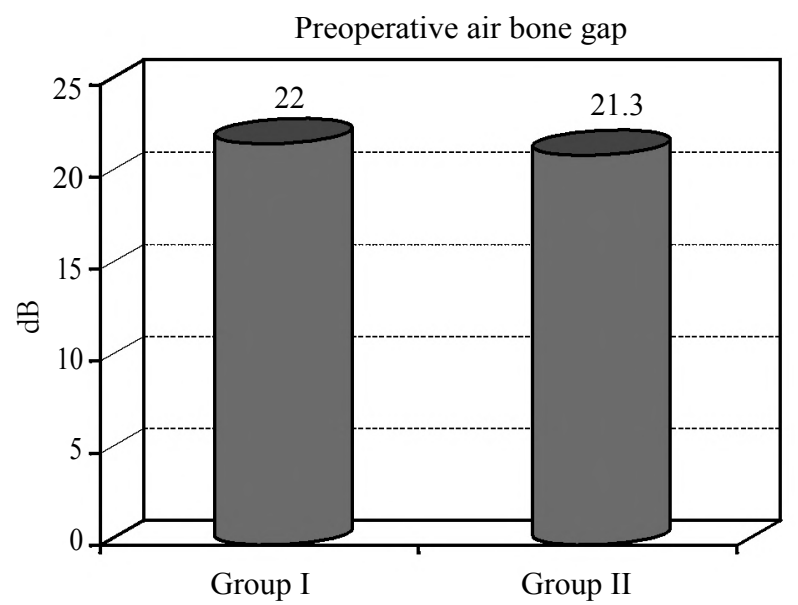

Fig. (18): Comparing preoperative Air Bone Gap in both groups.

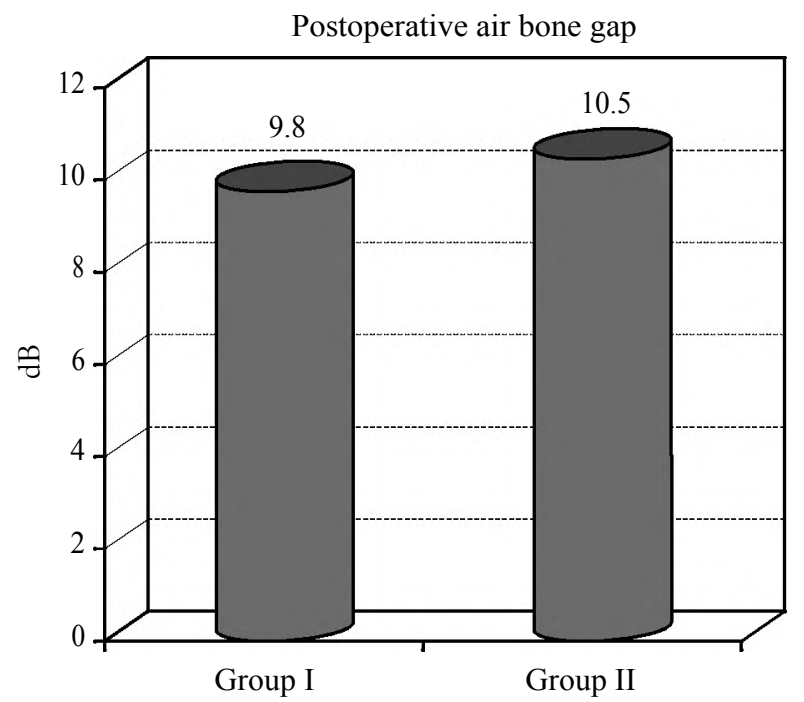

Fig. (19): Comparing postoperative Air Bone Gap in both groups.

The difference in the graft success rates between the 2 groups is statistically insignificant $(p>0.05)$, (Table 6 and Fig. 20).

Table (6): Success rate among both groups.

\begin{tabular}{lcccc}
\hline Characteristics & $\begin{array}{c}\text { Group I } \\
(\mathrm{n}=24)\end{array}$ & $\begin{array}{c}\text { Group II } \\
(\mathrm{n}=24)\end{array}$ & $t$ & $p$ \\
\hline Success & $20(83.3 \%)$ & $23(95.8 \%)$ & & \\
Failure: & & & & \\
$\quad \begin{array}{l}\text { Perforation } \\
\text { Lateralization }\end{array}$ & $4(16.7 \%)$ & $4(4.2 \%)$ & 2.009 & 3.480 \\
Blunting & - & - & & \\
Retraction & - & - & & \\
\hline
\end{tabular}

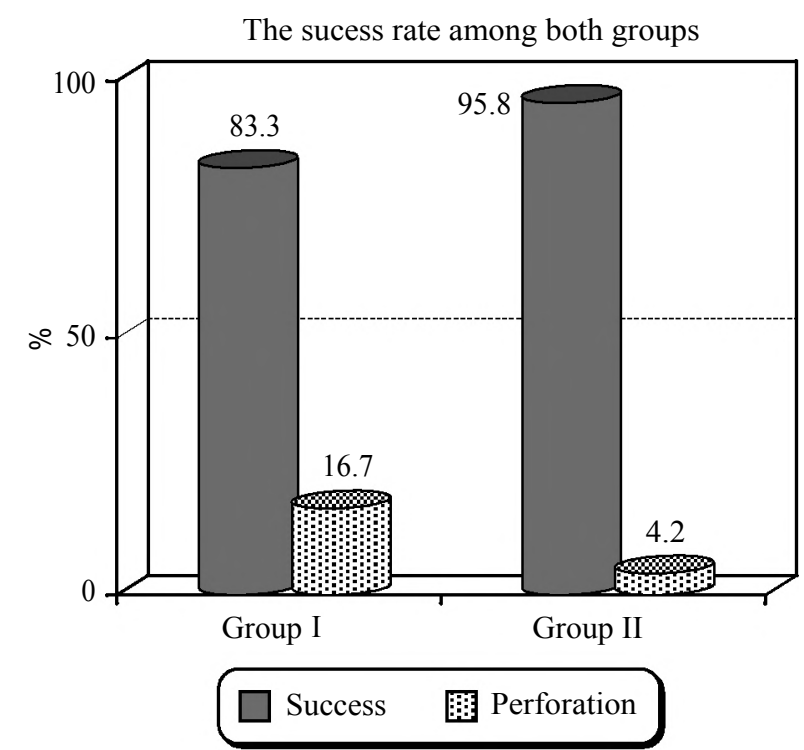

Fig. (20): Success rate among both groups. 


\section{Discussion}

It is often reported that the repair of large perforations is less successful than that of smaller perforations because it is technically more difficult $[7,8]$.

The absence of an adequate residual TM in subtotal perforations remains a challenge to otolaryngologists [9].

Advantages of temporalis fascia graft [10]:

1- Easily available in sufficient quantity.

2- Separate incision not required.

3- Adequately firm.

4- Thickness similar to TM.

5- Low basal metabolic rat.

Disadvantages of temporalis fascia graft [10]:

1- If it is not denuded properly of the muscles, then oxygen and the metabolic requirement increases and the graft may fail.

2- In revision cases, adequate graft may be difficult to obtain.

3- Graft retraction.

4- Graft medialization in cases of eustachian tube dysfunction.

Graft cartilage harvested from the concha or tragus is easy to obtain, thick, hard, resistant to resorption and retraction, and convenient for shaping according to the size of the perforation and the nature of the middle-ear pathology [11]

However, the risk of significant conductive hearing loss following cartilage tympanoplasty has always hampered routine acceptance of cartilage as a graft material [12].

In an attempt to increase the advantages of the cartilage-perichondrium composite graft while avoiding its disadvantages, Mansour et al., modified what is now termed a "cartilage-perichondrium composite ring graft". This was done by cutting and dissecting most of the central cartilaginous disc, leaving the graft with a peripheral cartilaginous ring $(2-3 \mathrm{~mm})$ attached to a unilateral firm, elastic, transparent sheet of perichondrium. In these authors' series, tympanic membrane perforations were completely healed using "cartilage-perichondrium composite ring grafting", in 18 cases of non cholesteatomatous,chronic, suppurative otitis media with different perforation sizes [13].

Removing most of the central cartilaginous disc while keeping a narrow $(2-3 \mathrm{~mm})$ peripheral rim with its normal harvest thickness makes the central part of the same thickness of normal tympanic membrane, this enabled rapid healing and no delay in hearing, and makes the central part translucent allowing good examination of the middle ear especially in the follow up in cases of cholesteatoma. Leaving peripheral $2-3 \mathrm{~mm}$ cartilaginous ring makes support of the graftespecially in the absence of fibrous annulus and prevent shrinkage of the graft or formation of retraction pockets without effect on the middle ear space [13].

The underlay or overlay graft techniques. Each of these approaches and techniques has its advantages and disadvantages [14]

The underlay technique is perhaps more commonly used worldwide; this technique is easier to perform and less time consuming and is more suitable for posterior perforations [14]. This technique has disadvantages, including a decreased mesotympanic space, medial displacement of the graft and lower success rate in subtotal and anterior perforations. Additionally, the technique has a lower risk for lateralization, and a more acceptable success rate, even in the hands of less-experienced surgeons [16]. In the overlay technique, there is a risk of graft lateralization, anterior blunting, delayed healing, stenosis of the external canal, epithelial pearls, and iatrogenic cholesteatoma. Despite its higher success in repairing anterior andsubtotal perforations, there is a consensus concerning the overlay technique being more technically challenging [17]

In our study the graft success rate in the overlay group (I) was $83.3 \%$. only 4 cases $(16.7 \%$ ) developed post operative perforations. In underlay group (II) the success rate was $95.8 \%$. Only one case $(4.2 \%)$ developed post operative perforation. The difference in graft success rates between the 2 groups is statistically insignificant $(p>0.05)$, as was the same result in other studies.

The underlay or overlay positioning of the graft does not significantly influence the rate of postoperative perforations or complications with the exception of epithelial pearls, which occur significantly more frequently following the overlay technique for perforations that require fibroepidermal cleaving across a large area [17].

On the other hand, Albirmawy used ring graft, comparing it with temporalis fascia in 82 patients with dry, non-cholesteatomatous ears and an intact ossicular chain. The graft success rate after at least one year of follow-up was 95 per cent for the ring graft group and 76.2 per cent for the fascia group; 
this difference was statistically significant. Moreover, the delayed post-operative perforation encountered in the ring graft group healed with conservative treatment, while this approach failed in cases of post-operative perforation in thefascia group [18]

In our study in ring group (II) the mean of $A B G$ preoperatively is $(21.3 \pm 7.6) \mathrm{dB}$ and the mean of ABG postoperatively is $(10.5 \pm 5.3) \mathrm{dB}$ so the mean

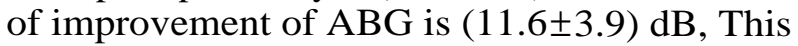
difference is highly statistically significant $(p<0.001)$. In the fascia group (I) the mean of ABG preoperative is $(22.0 \pm 7.7) \mathrm{dB}$ and the mean of ABG postoperative is $(9.8 \pm 4.5) \mathrm{dB}$ so the mean of improvement in $\mathrm{ABG}$ is $(12.6 \pm 5.2) \mathrm{dB}$. This difference ishighly statistically significant $(p<0.001)$. Comparison of the two groups ABG change results revealed statistically insignificant difference $(p>0.05)$, as it was in other studies.

In Albirmawy study..., Comparison of the two groups (ring group and fascia group)' audiological results did not reveal any statistically significant difference [18]

A lot of studies were done on different cartilage grafts to study their anatomical and functional results especially effect on hearing using thick cartilage graft which was proven that no significant difference on hearing using fascia or cartilage grafts [12]

Kazikdas et al., presented a comparison between results with fascia on 28 ears, and with underlay cartilage strips on 23 ears operated during a 6year period from 2000 to 2006. In both groups, the perforations were subtotal and the ossicular chain was intact, the ears were dry with normal middle ear mucosa at least one month before operation. In cartilage group, the $\mathrm{ABG}$ preoperative was $31.4 \pm 10.7 \mathrm{~dB}$ and postoperative was $22.4 \pm$ $12 \mathrm{~dB}$. In the fascia group, preoperative ABG was $42.2 \pm 14.6 \mathrm{~dB}$, and the postoperative $\mathrm{ABG}$ was $29.7 \pm 17 \mathrm{~dB}$. There was no significant difference between the two groups, but the cartilage group has a better hearing results [19]

Sapci et al., in 25 patients, closed dry inferior or dry subtotal perforations withan underlay cartilage-perichondrium composite island graft tympanoplasty. In the other, identical group of 25 patients the perforations were closed with underlay, temporalis fascia graft. In both groups, ossicular chain was intact. The mean age was 30 years, range 11-63 years. At the end of the first year of observation, graft survival was $92 \%$ in the cartilage group and $85 \%$ in the fascia group. The two meth- ods did not significantly in terms of hearing improvement [20].

\section{Conclusions:}

Both techniques we used in this study were very effective in closing subtotal large perforations of TM. healing failed in four cases in fascia group and only one case failed in Ring group. Ring group showed better healing results than Fascia group but the difference between both groups is statistically insignificant $(p>0.05)$.

Fascia group showed better hearing results [the change in $A B G$ in was (mean: 12.6 \pm 5.2$) \mathrm{dB}$ ] than the. Ring group [the change of $\mathrm{ABG}$ was (mean: 11.6 \pm 3.9$) \mathrm{dB}$ ] but the difference between both groups is statistically insignificant.

\section{Recommendations:}

This study needs to be repeated on a larger number of cases and needs a longer period of follow-up for better evaluation.

\section{Conflicts of interest:}

There are no conflicts of interest.

\section{References}

1- F.M. RIZER: Overlay versus underlay tympanoplasty. Part I: Historical review of the literature, Laryngoscope, Vol. 107, No.12, pp. 1-25, 1997.

2- R. EWEHRS: Grafting techniques, otolaryngologic Clinics of North America, Vol. 32, No. 3, pp 443-445, 1999.

3- DORNHOFFERJ L.: Cartilagetympanoplasty. Otolaryngol. Clin. North. Am. Dec., 39 (6): 1161-76, 2006.

4- HAIM GAVRIEL and EPHRAIM EVIATAR: Inferior Flap Tympanoplasty: A Novel Technique for Anterior Perforation Closure. Bio Med. Research .International., Volume 2013, Article ID 758598, 4 pages, 2013.

5- M.H. MANSOUR, M.H. ASKAR and O.A.A LBIRMAWY: The cartilage-perchondrial (ring graft) in myringoplasty: Egypt. J. Otolaryngol., Vol. 22, No. 1, January, 7-10, 2005.

6- M.H. MANSOUR, M.H.ASKAR and O.A. ALBIRMAWY: Repair of tympanic membrane perforation using a modified cartilage-perichondrium composite ring graft. HOW I DO IT: The Journal of Laryngology \& Otology/Volume 120/issue 11/November, pp. 952-954, 2006.

7- LEE P., KELLY G. and MILLS R.P.: Myringoplasty: Does size of the perforation matter? Clin.Otolaryngol., 27: 331-334. doi: 10.1046/j.1365-2273.2002. 00590, 2002.

8- INDOREWALA S.: Dimensional stability of free fascia grafts: Clinical application. Laryngoscope. 115: 278-282. doi: 10.1097/01.mlg.0000154733. 54152.54, 2005.

9- ADKINS W.Y. and WHITE B.: Type I tympanoplasty: influencing factors. Laryngoscope, 94: 916-918, doi: 10.1288/00005537-198407000-00011], 1984. 
10- SUNIL S. NICHLANI, et al.: Reconstruction of the Tympanic Membrane with Partial Tragal cartilage Graft Versus Temporalis Fascia Graft. Bombay Hospital Journal, Vol. 52, No. 2, 2010.

11-DORNHOFFER J.L.: Cartilage tympanoplasty. Otolaryngol. Clin. North. Am., 39: 1161-76, 2006.

12- DORNHOFFER J.: Cartilage tympanoplasty: Indications, technique, and outcomes in a 1,000-patient series. Laryngoscope, 112: 1944-56, 2003.

13- MANSOUR M.H., ASKAR M.H. and ALBIRMAWY O.A.: Repair of tympanic membrane perforation using a modified cartilage-perichondrium composite ring graft. J. Laryngol. Otol., 120: 952-4, 2006.

14- RIZER F.M.: Overlay versus underlay tympanoplasty. Part I: Historical review of the literature. Laryngoscope, 107: 1-25, 1997.

15- GERLINGER I., RÁTH G., SZANYI I., et al.: Myringoplasty for anterior and subtotal perforations using KTP532, laser. Eur. Arch. Otorhinolaryngol., 263: 816-819, doi: 10.1007/s00405-006-0077-z, 2006.

16- GERSDORFF M., GERARD J. and THILL M.: Overlay versus underlay tympanoplasty: Comparative study of 122, cases. Rev. Laryngol. Otol. Rhinol., 24: 15-2, 2003.

17- Rev. Laryngol. Otol. Rhinol. (Bord)., 124 (1): 15-22. In study of Overlay versus underlay tympanoplasty. Comparative. Study of 122, Cases, 2003.

18- ALBIRMAWYOA.: Comparison between cartilageperichondrium composite 'ring' graft and temporalis fascia in type one tympanoplasty in children. J. Laryngol. Otol., 124: $967-74,2010$

19- KAZIKDAS K.C., ONAL K., BOYRAZ I. and KARABULUT E.: Palisade cartilage tympanoplasty for management of subtotal perforations; a comparison with temporalis fascia technique. Eur. Arch. Otorhinolaryngol., 264: 985-9, 2007.

20- SAPCI T., ALMAC S., USTA C., KARAVUS A., MERCANGOZ E. and EVCIMIK M.F.: Comparison between tympanoplasties with cartilage-perichondrium composite graft and temporalis fascia graft in terms of hearing levels and healing. [In Turkish] Kulak. Burun. Bogaz. Ihtis. Derg., 16: 255-60, 2006.

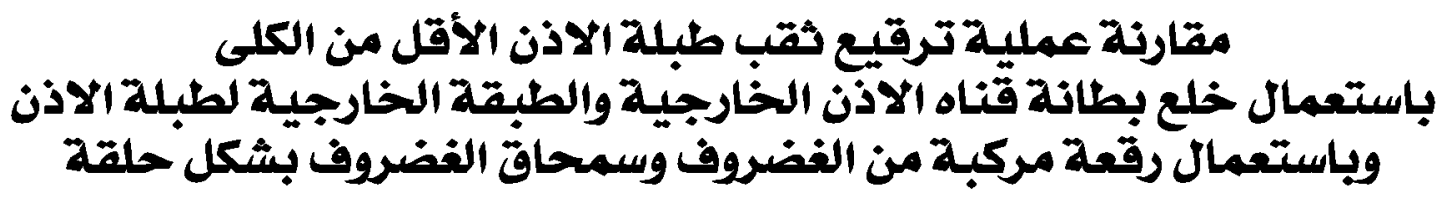

هذه الدراسة دراسة مستقبلية انعقدت بقسم الأنن والأنف والحنجرة بمستشفى جامعة طنطا على ثمانية واربعقن حالة متتابعة من حالات

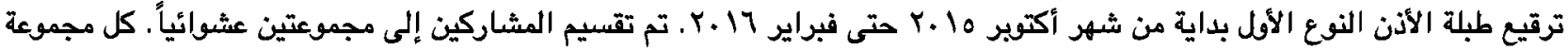

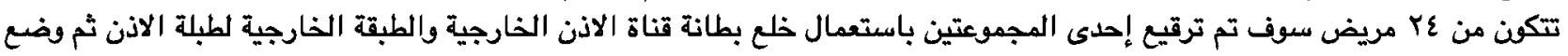

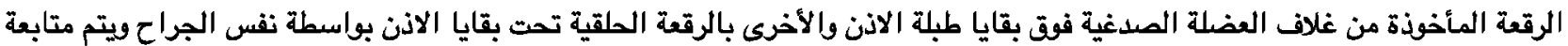

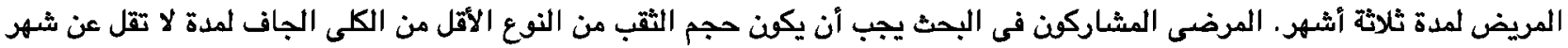

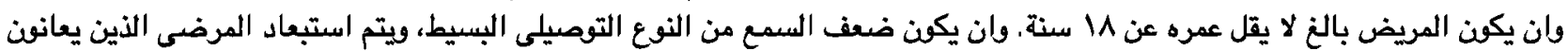
من تسوس بالاذن أو الذين يحتاجون إلى اصلاح عظيمات الاذن أو بعد عمليات فاشلة لترقيع طبلة الانن.

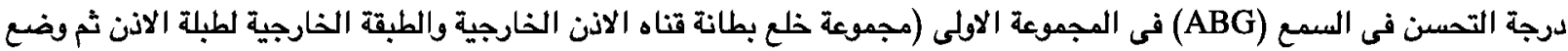

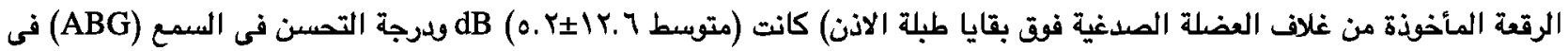

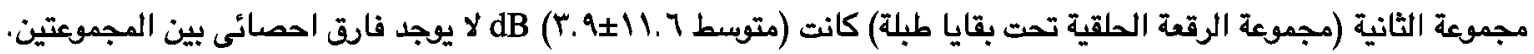

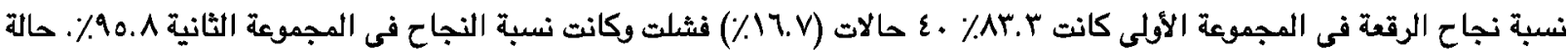

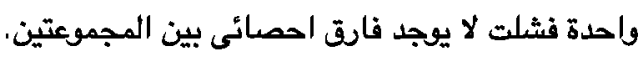

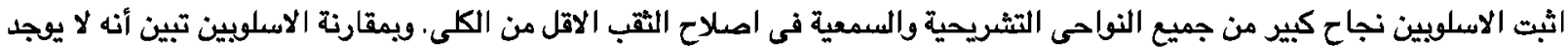

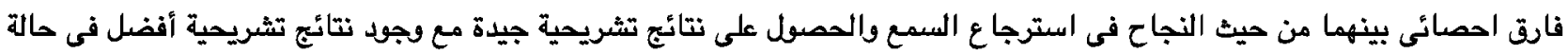

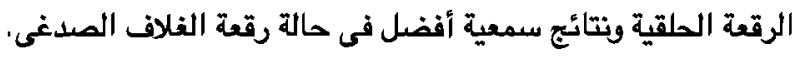

